\title{
Lean Six Sigma Applied to Process Performance and Improvement Model for the Development of Electric Scooter Water-cooling Green Motor Assembly
}

\section{Abstract}

In response to the environmental issues triggered by global warming, worldwide companies gradually put the factor of carbon emission into the process of product life cycle, developing green technology or adopting cleaner production aimed at sustainable development. Lean Six Sigma has advantages of cutting waste and facilitating process improvements as well as system analysis, helping enterprises create the overall business benefits in the value chain. Used in the renewable energy industry, it can promote the Triple Bottom Line (TBL), the performance of sustainable production for corporate profit, social responsibility, and environmental responsibility. Therefore, this study took the process performance of the electric scooter water-cooling green motor manufactured in Taiwan with the world's highest density of scooters as a case study. The developed performance evaluation and improvement model for manufacturing scheduling and process quality achieved the goal of economic benefits of enhancing process quality performance by shortening manufacturing scheduling and reducing process variations with Lean Six Sigma. 
Besides, they could respond to the policy of energy saving and carbon reduction replacing the traditional scooters of high carbon emissions with the electric scooters of low emissions. Furthermore, they could bring enterprises into harmony with economic benefits, ecological benefits, and social benefits.

Keywords: Lean Six Sigma, Electric scooter green motor, Triple Bottom Line, energy saving and carbon reduction, sustainable development 


\section{Introduction}

According to the research done by Folster (2010), Dejan (2013), and Almer and Winkler (2017), the awareness of environmental protection has been continuously rising from the Kyoto Protocol of 1997 to the present 21st century. The Paris Climate Change Conference 2015 is a milestone for the global climate governance, encouraging the low carbon energy transition and urging the globe to march toward the target of green growth and zero carbon energy. Based on the study conducted by the Industrial Development Bureau of the Ministry of Economic Affairs in Taiwan, currently the carbon emissions of electric scooters in the area of Taiwan are less than $50 \%$ of those of fuel-powered scooters. Besides, the research done by Lambert (2017) and Staffel et al. (2017) also shows that the development of green energy can help the electric scooters' carbon emissions drop further. Moreover, Taiwan and Southeast Asian countries have much higher populations using scooters as a way of transportation than any other places in the world. Thus, to cope with the promotion and development of green electric scooters, the Taiwanese government actively promotes the development of the green-energy electric scooter industry, in order to reduce the fuel-powered scooters' impact ratio to air pollution.

In addition, according to Chen and Lyu (2009), Jacobs et al. (2015), Garza-Reyes et al. (2016), Thomas et al. (2016), Cherrafi et al. (2017), and Bellisario \& Pavlov 
(2018), Lean Six Sigma is a combination of lean production and Six Sigma thoroughly eradicating non-value-added waste and shortening the time of process. Also, it can help reduce the variation in the manufacturing process as well as the product defect rate (Srinivasan et al. (2016)). Currently, a large number of researchers, such as Kumar et al. (2006), Andrew and Okafor (2009), Lee and Wei (2010), Wang and Chen (2010), Hardeman and Goethals (2011), Jacobs et al. (2015), Thomas et al. (2016) and so on, apply Lean Six Sigma to the industries and receive remarkable outcomes. Besides, according to Antony et al. (2017) (public sector), Alsyouf et al. (2018) (aircraft industry), Gupta et al. (2018) (higher education), Raja Sreedharan et al. (2018) (manufacturing industry), Shamsuzzaman et al. (2018) (communications industry), Trzeciak et al. (2018) (Medical Services) and Yadav et al. (2018) (manufacturing industry), most of literatures related to Lean Six Sigma focused on the financial and economic performance, whereas only a few literatures emphasized the applications to promoting 3TBL/sustainable production or sustainable improvement. When producing the electric scooter water-cooling motors, there must be high process accuracy and timeliness. At the same time, product quality must be controlled through continuous improvement and immediate feedback, in order to achieve the goals of 3TBL/sustainable production and sustainable improvement. Owing to this, this study selects the systematic method, Lean Six Sigma, to reach the goal. 
As stated above, Lean Six Sigma has advantages of cutting waste and facilitating process improvements as well as system analysis, helping enterprises create the overall business benefits in the value chain. Used in the renewable energy industry, it can urge enterprises to perform well in the TBL sustainable production. In addition, in response to the environmental issues triggered by global warming, numerous companies put the factor of carbon emission into the consideration of production, developing green technology or adopting cleaner production aimed at sustainable development. Therefore, this study took the "electric scooter water-cooling green motor" manufactured in Taiwan, a region with the world's highest density of scooters (In 2017, the number of scooters was $806.56 / \mathrm{km} 2$.), as a case study. The green motor produced by the case company combining the concepts of green energy and cleaner production differs from the general motor using air to cool down the high temperature generated by operation. Instead, the green motor adopts the water-cooling and circulating method to perform a more efficient cooling way, so that it can better the output efficiency of motor operation and reduce the impact on our environment. Lean Six Sigma can help bring enterprises into harmony with economic benefits, ecological benefits, and social benefits.

The remainder of this paper is organized as follows. In Sec. 2, this study will briefly introduce the process of electric scooter water-cooling green motor assembly 
and collect customer (VOC) as well as value stream mapping (VSM) to find out the non-valued parts in the green motor process. In Sec. 3, targeting at the non-valued parts, such as the manufacturing schedule performance and process quality level, this study will Six Sigma quality indices and manufacturing schedule performance indices. In Sec. 4, this study will deduce the evaluation and testing model for Six Sigma quality indices as well as manufacturing schedule performance and sort out the results to form an evaluation form for the electric scooter water-cooling motor manufacturing performance, in order to benefit the subsequent analyses and improvement tasks. In Sec. 5, the cause-and-effect diagram will be applied to find out the control factors which influenced the process. The Taguchi method will be used to figure out the best parameter setting to promote the process performance. Meanwhile, Standard operation procedure will be adopted to assist the tool room management inside the factory to enhance the tool management and ensure the processing quality. Conclusions will be presented in Sec. 6 .

\section{Introduction to the analytic structure and process of the electric scooter water-cooling green motor assembly}

\subsection{Analytic structure}


In this paper, Lean Six Sigma is used as an analytic method, and the DMAIC procedure of Six Sigma is used as a framework, to develop a process performance evaluation and improvement model for an electric scooter water-cooled green motor assembly. First, the voice of customer is paired up with the value stream mapping to find out the value-added activities in the process, in order to find out the problems that need to be improved. Next, this study explores the important processes of the motor assembly and summarizes the important quality characteristics. Manufacturing schedule performance indices are proposed based on important processes, and Six Sigma evaluation indices are come up with based on important quality characteristics to evaluate manufacturing schedule performance and process quality standards. This study then deduces the confidence intervals corresponding to Six Sigma quality indicators and manufacturing schedule performance indicators to evaluate and verify the performance indicators, in order to review the process characteristics and quality characteristics that need to be improved. The cause-and-effect diagram and the Taguchi method are used to analyze the control factors which influenced the process and figured out the best parameter setting, aiming to promote the process performance as well as assist the tool room management inside the factory. Last, the control chart is developed to continuously monitor the quality of the process. Lean Six Sigma can not only shorten the manufacturing time but also reduce the process variation to create 
business value, and then the goal of 3TBL/sustainable production and sustainable improvement can be achieved

\subsection{Introduction to manufacturing process}

As the above-mentioned, the water-cooling green motor assembly of the electric scooter manufactured by the case-study company is more complicated than and different from that of the commonly sold electric scooter in the market which uses air impact to cool down the high temperature resulted from the motor's operation. The water-cooling method is adopted to conduct a more efficient way of lowering the temperature to enhance the output efficacy of the motor's operation. The watercooling flow path created by the case-study company is to enclose the entire motor to stabilize its working temperature, so the structure of the motor consists of two major parts - inner water case and outer water case, called as the motor assembly in this paper. Thus, the motor assembly is divided into 2 major processes: inner water case underline process and outer water case inner-hole process. After the preprocessed multiple processing procedures, the airtight machine will be sent to conduct an air tightness test. The entire process is displayed in Fig. 1. 


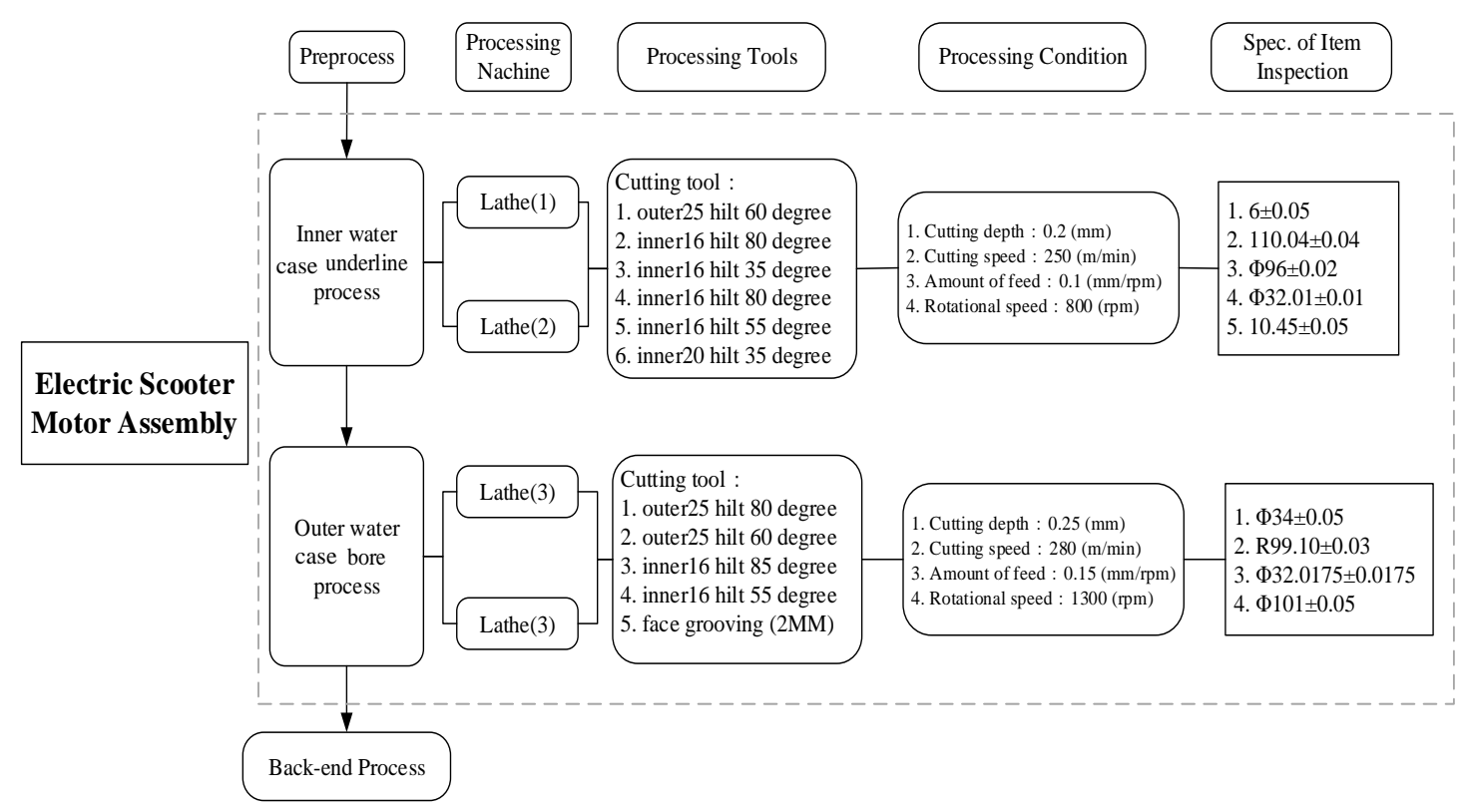

Fig. 1 Process flow chart of the electric scooter water-cooling green motor assembly

In the light of the electric scooter water-cooling green motor assembly, this study adopts Lean Six Sigma as an improvement method, which can not only reduce waste but also create the overall business benefits in the value chain. If the voice of customer (VOC) can take several factors, such as environmental protection, green energy design, cleaner production, and reducing carbon emissions, into consideration, it can help enterprises move toward the goals of economic benefits, ecological benefits, and social benefits into harmony. This study presents the voice of customer (VOC) as shown in Table 1. Therefore, in the definition stage of Lean Six Sigma, we discover the customers' problems related to product quality and environmental protection and draw the current value stream mapping (VSM). Only when the non-value-added reasons caused by the motor assembly process are confirmed and the 
problem that needs to be improved first is identified, the entire production capacity and performance can largely enhance.

Table 1 VOC chart of the electric scooter water-cooling green motor

\begin{tabular}{|c|c|c|}
\hline Source of data & Sales department & $\begin{array}{l}\text { Quality control department/ } \\
\text { manufacturing department }\end{array}$ \\
\hline Source of voice & External VOC & Internal VOC \\
\hline $\begin{array}{l}\text { Customers' } \\
\text { opinions }\end{array}$ & $\begin{array}{ll}\text { 1. } & \text { Ill product quality } \\
\text { 2. Delays of shipments } \\
\text { 3. }\end{array}$ & $\begin{array}{ll}\text { 1. } & \text { Ill airtightness } \\
\text { 2. } & \text { Insufficient stock } \\
\text { 3. } & \text { Long processing time }\end{array}$ \\
\hline Possible causes & 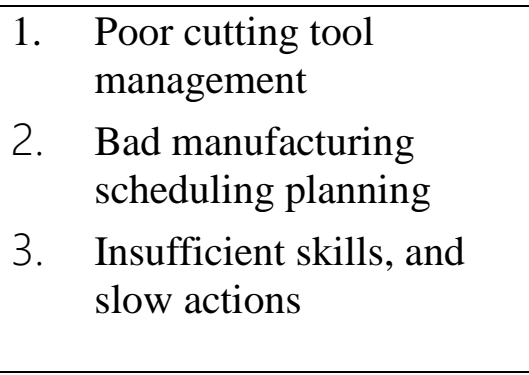 & $\begin{array}{l}\text { 1. Bad process quality } \\
\text { 2. Ill control of the time of } \\
\text { incoming and outgoing } \\
\text { shipments } \\
\text { 3. Problems of cutting tool } \\
\text { management and cutting } \\
\text { tool quality }\end{array}$ \\
\hline
\end{tabular}

As mentioned above, this study uses VSM to understand the process flow of the electric scooter water-cooling green motor, able to show all the statuses of the process, and also able to know all of the value directions and the required time, as displayed in Fig. 2. According to the drawn VSM, the values of the required time information can be obtained, and the total cycle time of the process can be computed to judge whether the process can achieve lean. 


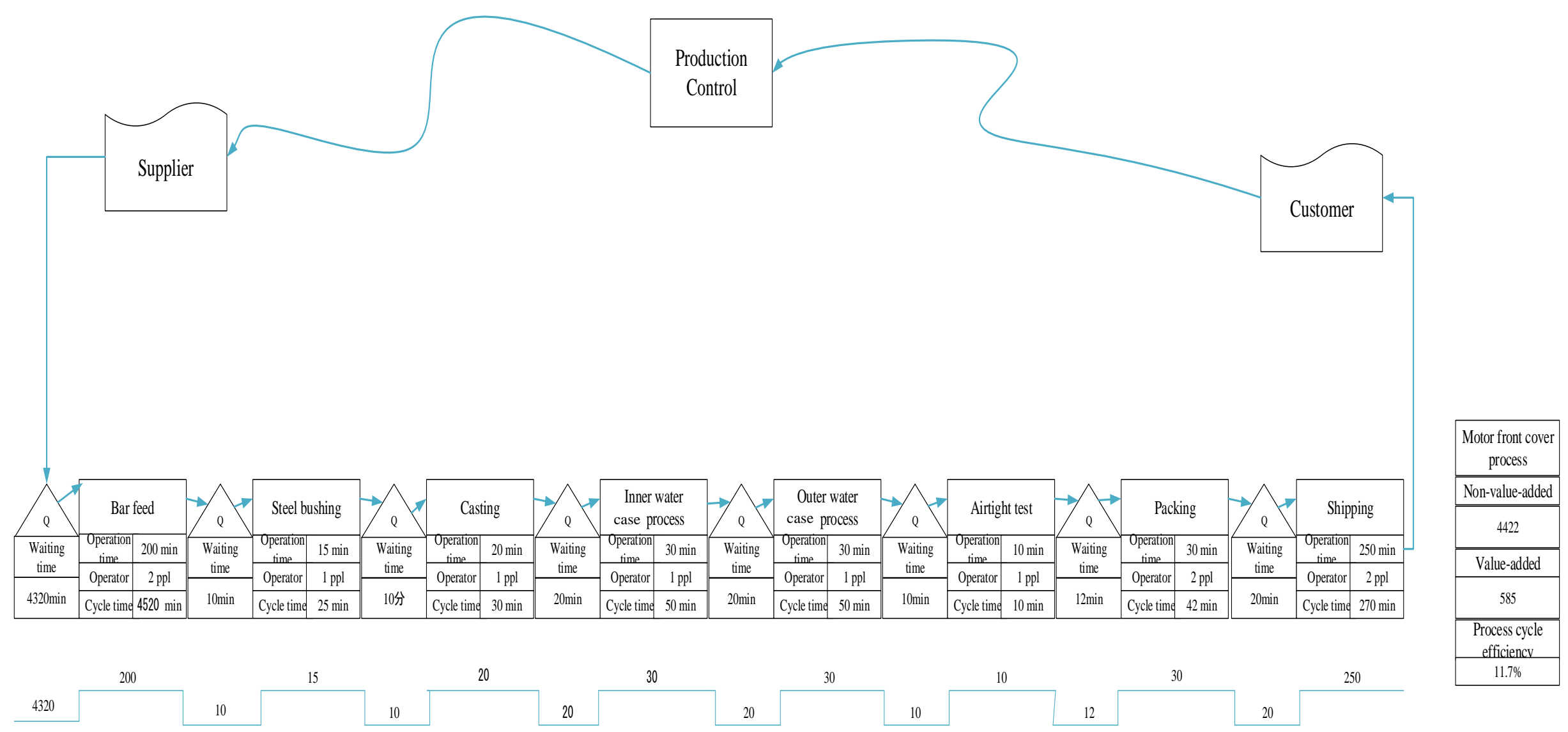

Fig.2 Value stream mapping of the electric scooter water-cooling green motor 
This study, based on the previously stated VOC and VSM, respectively lists the goals for improvement and their corresponding critical quality indices. Next, concerning whether the critical quality indices correspond to VOC, space for improvement can be rated as weight. Besides, according to these critical quality indices indicating whether there is a project taking place in the company, all the present performances of the critical quality indices are listed, and the target performance is seen as an evaluation to see whether these critical quality indices will be brought into the range of the project, as demonstrated in Table 2. Lastly, the aim of getting the project is to lift the process quality level to reduce the process defect rate (estimated to lower 5\% of defect rate) and the airtightness defect rate (estimated to lower 4\%); meanwhile, it can boost the manufacturing efficiency to shorten the manufacturing time (estimated to lower at least $13 \%$ of time waste).

Decreasing the defect rate of air tightness is to use the green motor manufactured by the case company combining the concepts of green energy and cleaner production and employ the water-cooling and circulating method to perform a more efficient cooling approach, so that the motor operation output efficiency can enhance. Besides, the green motor can reduce carbon emissions and achieve the environmental protection of green energy products. Furthermore, Lean Six Sigma can help promote the process quality as well as reduce the defect rate of air tightness. 
Table 2 Analysis chart for critical quality indices of the process

\begin{tabular}{|c|c|c|c|c|c|c|c|}
\hline \multirow[b]{2}{*}{$\begin{array}{l}\text { Voice of } \\
\text { customer } \\
\text { (VOC) }\end{array}$} & \multirow[b]{2}{*}{$\begin{array}{l}\text { Item for } \\
\text { improvement } \\
\text { (VSM) }\end{array}$} & \multirow[b]{2}{*}{$\begin{array}{l}\text { Critical } \\
\text { quality } \\
\text { index } \\
\text { (CTQ) }\end{array}$} & \multicolumn{3}{|c|}{ Weight } & \multirow[b]{2}{*}{$\begin{array}{l}\text { Current } \\
\text { perfor } \\
\text { mance }\end{array}$} & \multirow[b]{2}{*}{$\begin{array}{c}\text { Target } \\
\text { performa } \\
\text { nce } \\
\text { (SIPOC) }\end{array}$} \\
\hline & & & $\begin{array}{c}\text { Whether it } \\
\text { corresponds } \\
\text { to VOC } \\
(\mathrm{Y} \rightarrow 5 \\
\mathrm{N} \rightarrow 0)\end{array}$ & $\begin{array}{l}\text { Space for } \\
\text { improvem } \\
\text { ent }(9,6,3)\end{array}$ & Total & & \\
\hline $\begin{array}{l}\text { Ill product } \\
\text { quality }\end{array}$ & $\begin{array}{l}\text { Poor process } \\
\text { quality and } \\
\text { cutting tool } \\
\text { management }\end{array}$ & $\begin{array}{c}\text { Process } \\
\text { defect rate }\end{array}$ & 5 & 9 & 14 & $15 \%$ & $10 \%$ \\
\hline $\begin{array}{l}\text { Delays of } \\
\text { shipments }\end{array}$ & $\begin{array}{c}\text { Bad } \\
\text { manufacturing } \\
\text { scheduling } \\
\text { planning }\end{array}$ & $\begin{array}{l}\text { Manufact } \\
\text { uring } \\
\text { schedulin } \\
\text { g }\end{array}$ & 5 & 3 & 8 & & \\
\hline \multirow[t]{3}{*}{$\begin{array}{c}\text { Ill } \\
\text { airtightnes } \\
\text { S }\end{array}$} & $\begin{array}{c}\text { Assembly } \\
\text { problem, and } \\
\text { ill quality of } \\
\text { spare parts }\end{array}$ & $\begin{array}{l}\text { Airtightne } \\
\text { ss defect } \\
\text { rate }\end{array}$ & 5 & 6 & 11 & $5 \%$ & $1 \%$ \\
\hline & $\begin{array}{l}\text { The time of } \\
\text { inner water } \\
\text { case process is } \\
\text { too long }\end{array}$ & $\begin{array}{l}\text { The time } \\
\text { of inner } \\
\text { water case } \\
\text { process }\end{array}$ & 5 & 6 & 11 & $25 \%$ & $12 \%$ \\
\hline & $\begin{array}{l}\text { The time of } \\
\text { outer water } \\
\text { case process is } \\
\text { too long }\end{array}$ & $\begin{array}{l}\text { The time } \\
\text { of outer } \\
\text { water case } \\
\text { process }\end{array}$ & 5 & 6 & 11 & $27 \%$ & $12 \%$ \\
\hline
\end{tabular}

Hence, this paper will target at these two processes to develop the manufacturing scheduling performance indices and six sigma evaluation indices. Based on the spirit of Lean Six Sigma, the evaluations and analyses of the manufacturing scheduling performance indices and process quality level are conducted as well. Thus, this study will also aim for the improvement of the tool room management. 


\section{Manufacturing performance indices}

As the above-mentioned, the electric water-cooling green motor assembly includes the inner water case underlining process and the outer water case inner-hole process, as shown in Figure 1.There are 5 quality characteristics of the Normal The Better (NTB) in the inner water case underlining process, while there are 4 quality characteristics of NTB in the outer water case inner-hole process. The tolerance specifications of these 9 quality characteristics are displayed in Table 3 . This study proposes the evaluation model of two important indicators which are manufacturing quality level and manufacturing schedule performance. In addition to reaching the goal of promoting the economic benefits of process quality performance by using Lean Six Sigma to shorten the manufacturing schedule as well as process variations, this case study develops green technology and adopts the method of cleaner production in response to the policy of energy saving and carbon reduction, in order to help enterprises move forward to meet the goal of sustainable development concerning economic benefits, ecological benefits, and social benefits.

Table 3 Quality characteristic specs. of the electric scooter green motor assembly

\begin{tabular}{|l|l|}
\hline \multicolumn{1}{|c|}{ Item } & Tolerance Spec. $(\mathrm{mm})$ \\
\hline$I$. Inner water case underline process & \\
\hline 1. Motor front cover height & $\Phi 6 \pm 0.05$ \\
\hline
\end{tabular}




\begin{tabular}{|l|l|}
\hline 2. Motor front cover circle diameter & $\Phi 110.04 \pm 0.04$ \\
\hline 3. Motor front cover locking hole center & $\Phi 96 \pm 0.02$ \\
\hline 4. Bearing circle diameter & $\Phi 32.01 \pm 0.01$ \\
\hline 5. Bearing depth & $10.45 \pm 0.05$ \\
\hline II. Outer water case bore process & \\
\hline 1. Small motor cover circle diameter & $\Phi 34 \pm 0.05$ \\
\hline 2. Motor rotor circle diameter & $\mathrm{R} 99.10 \pm 0.03$ \\
\hline 3. Body engagement hole circle diameter & $\Phi 32.0175 \pm 0.0175$ \\
\hline 4. Body engagement hole center & $\Phi 101 \pm 0.05$ \\
\hline
\end{tabular}

In regard to quality, this study will employ the concept of Chen et al. (2017) to develop the evaluation model for six sigma quality indicators. As to the manufacturing schedule, based on the theories of Huang and Chen (2004) and Chen and Huang (2006), the speed of manufacturing schedule will influence the manufacturing quality, so the manufacturing schedule must be moderate. Therefore, this study develops the evaluation model for the manufacturing schedule performance indicators. Next, these two manufacturing performance indicators will be discussed respectively.

\subsection{Six sigma quality indices}

It can be seen from Table 1 that the electric scooter water-cooling green motor assembly includes 2 processes, the inner water case underline process and the outer water case bore process, with 9 nominal-the-best quality characteristics in total. This paper assumes that random variable $X_{a b}$ represents the normal process distribution 
of process $a$ and quality characteristic $b$, and the process mean is $\mu_{a b}$ and the process variable number is $\sigma_{a b}^{2}$, namely $X_{a b} \sim N\left(\mu_{a b}, \sigma_{a b}^{2}\right)$. As noted by Chang et al. (2014), if quality characteristic $X$ is nominal-the-better (NTB) type, then $L S L_{a b} \leq X_{a b}<U S L_{a b}$. Then, this paper, through the change of variables, lets

$$
Y_{a b}=\left\{\begin{array}{l}
\frac{X_{I b}-T_{I b}}{d_{I b}}, b=1,2,3,4,5 \\
\frac{X_{I I b}-T_{I I b}}{d_{I I b}}, b=1,2,3,4
\end{array}\right.
$$

The specifications of these 9 quality characteristics are all converted into $\left(L S L_{a b}, T_{a b}, U S L_{a b}\right)=(-1,0,1)$, where $L S L_{a b}$ is the lower specification limit, $T_{a b}$ is the target, and $U S L_{a b}$ is the upper specification limit. According to the theory of Chen et al. (2017), the six sigma quality indices of these 9 quality characteristics are defined as follows:

$$
Q_{p k a b}=\operatorname{Min}\left\{Q_{p 1 a b}, Q_{p 2 a b}\right\}
$$

where

$$
Q_{p 1 a b}=\frac{1-\mu_{a b}}{\sigma_{a b}}+1.5 \text { and } Q_{p 2 a b}=\frac{1+\mu_{a b}}{\sigma_{a b}}+1.5 .
$$

Let $E_{a b}^{+}=\left(Y_{a b}<+1\right)$ and $E_{a b}^{-}=\left(Y_{a b}>-1\right)$, then

$$
\begin{aligned}
& p\left(E_{a b}^{+}\right)=p\left(Y_{a b}<+1\right)=p\left(Z<\frac{1-\mu_{a b}}{\sigma_{a b}}\right)=\Phi\left(Q_{\text {puab }}-1.5\right) \\
& p\left(E_{a b}^{-}\right)=p\left(Y_{a b}>-1\right)=p\left(Z<\frac{1+\mu_{a b}}{\sigma_{a b}}\right)=\Phi\left(Q_{\text {plab }}-1.5\right) .
\end{aligned}
$$


Therefore, the event $E_{a b}=E_{a b}^{+} \cap E_{a b}^{-}=\left(-1 \leq Y_{a b} \leq+1\right)$ represents the event of good products which meets the specification requirements for process $a$ and quality characteristic, and its yield is

$$
p_{a b}=p\left(E_{a b}\right)=p\left(E_{a b}^{+} \cap E_{a b}^{-}\right)=p\left(-1 \leq Y_{a b} \leq+1\right)
$$

Based on De Morgan theorem and Boole's inequality, we have

$$
p_{a b}=P\left(E_{a b}^{+} \cap E_{a b}^{-}\right) \geq 1-P\left(\left(E_{a b}^{+}\right)^{C}\right)-P\left(\left(E_{a b}^{-}\right)^{C}\right) \geq 2 \Phi\left(Q_{p k a b}-1.5\right)-1
$$

Obviously, if its compliment set $E_{a b}^{C}$ means the event of defective products, then

$$
q_{a b}=p\left(E_{a b}^{C}\right)=1-p_{a b} \leq 2-2 \Phi\left(Q_{p k a b}-1.5\right)
$$

Similarly, let $E_{a}=\bigcap_{b} E_{a b}$, then $E_{a}$ represents the event of good products for the inner water case underline process $(a=I)$ or the outer water case bore process $(a=I I)$.

Based on De Morgan theorem and Boole's inequality, we have

$$
\left\{\begin{array}{l}
p_{a}=p\left(E_{a}\right)=p\left(\bigcap_{b} E_{a b}\right) \geq 1-\sum_{b} p\left(E_{a b}^{C}\right) \geq 1-2 \times \sum_{b}\left(1-\Phi\left(Q_{p k a b}-1.5\right)\right) \\
q_{a}=p\left(E_{a}^{C}\right)=1-p_{a} \leq 2 \times \sum_{b}\left(1-\Phi\left(Q_{p k a b}-1.5\right)\right)
\end{array}\right.
$$

According to the above equation, this paper defines the process quality indices of these 2 processes are as follows:

$$
Q_{p k a}=\Phi^{-1}\left\{1-\sum_{b}\left(1-\Phi\left(Q_{p k a b}-1.5\right)\right)\right\}+1.5
$$

Based on Eq. (4) and Eq. (5), we have $\sum_{b}\left(1-\Phi\left(Q_{p k a b}-1.5\right)\right)=1-\Phi\left(Q_{p k a}-1.5\right)$ and 


$$
p_{a} \geq 2 \times \Phi\left(Q_{p k a}-1.5\right)-1
$$

When the quality level of these 2 processes reaches $k^{\prime} \sigma\left(Q_{p k a}=k^{\prime}\right)$, then the process yield $p_{a}$ will be least $2 \times \Phi\left(k^{\prime}-1.5\right)-1$. For example, when the process quality level reaches $4.5 \sigma$, then its process yield $p_{a}$ will be least $2 \times \Phi(4.5-1.5)-1=99.73 \%$.

For the same reason, let $E_{T}=\bigcap_{a} E_{a}$, then $E_{T}$ means the event of good products of the electric scooter green motor assembly. Based on De Morgan theorem and Boole's inequality, we have

$$
\begin{aligned}
p_{T} & =p\left(E_{T}\right)=p\left(\bigcap_{a} E_{a}\right)=p\left(\bigcap_{a, b} E_{a b}\right) \\
& \geq 1-\sum_{a} \sum_{b} p\left(E_{a b}^{C}\right) \geq 1-2 \times \sum_{a} \sum_{b}\left(1-\Phi\left(Q_{p k a b}-1.5\right)\right)
\end{aligned}
$$

According to the above equation, this paper defines the process quality indices of the electric scooter green motor assembly as follows:

$$
Q_{p k}=\Phi^{-1}\left\{1-\sum_{a} \sum_{b}\left(1-\Phi\left(Q_{p k a b}-1.5\right)\right)\right\}+1.5
$$

Based on Eq. (6) and Eq. (7), we have $\sum_{a} \sum_{b}\left(1-\Phi\left(Q_{p k a b}-1.5\right)\right)=1-\Phi\left(Q_{p k}-1.5\right)$ and

$$
p_{T} \geq 2 \times \Phi\left(Q_{p k}-1.5\right)-1
$$


When the quality level of the electric scooter green motor assembly reaches $k \sigma$ $\left(Q_{p k}=k\right)$, then its process yield $p_{T}$ will be ensured to be at least $2 \times \Phi(k-1.5)-1$.

To sum up, the electric scooter water-cooling green motor assembly consists of the inner water case underline process $(a=I)$ and the outer water case bore process $(a$ $=I I$ ), with 9 important quality characteristics included. If the process quality level of the motor assembly is requested to reach $k \sigma$, then the quality level of the inner water case underline process can be asked to reach $k_{I}^{\prime} \sigma$ and the quality level of the outer water case bore process can be asked to reach $k_{I I}^{\prime} \sigma$. According to the theories of Chen et al. (2006) and Wang et al. (2011), the quality levels of these 2 processes must be higher than the quality level of the motor assembly. Similarly, suppose the process quality levels of the 9 important quality characteristics are asked to be equal and set as $k^{\prime \prime} \sigma$, then the process quality levels of the 9 important quality characteristics also must be higher than the quality levels of the 2 processes, that is $k<k_{I I}^{\prime}<k_{I}^{\prime}<k^{\prime \prime}$, where $k_{I I}^{\prime}<k_{I}^{\prime}$ because there are 5 important quality characteristics in the inner water case underline process while there are 4 important quality characteristics in the outer water case bore process. Based on Eq. (5) and Eq. (7), we have

$$
\begin{aligned}
& k_{I}^{\prime}=\Phi^{-1}\left(1-5 \times\left[1-\Phi\left(k^{\prime \prime}-1.5\right)\right]\right)+1.5 \\
& k_{I I}^{\prime}=\Phi^{-1}\left(1-4 \times\left[1-\Phi\left(k^{\prime \prime}-1.5\right)\right]\right)+1.5
\end{aligned}
$$




$$
k^{\prime \prime}=\Phi^{-1}\left(1-\frac{1}{9} \times[1-\Phi(k-1.5)]\right)+1.5
$$

According to this result, if the process quality level of the electric scooter green motor assembly is asked to reach $k \sigma\left(Q_{p k}=k\right)$, then we must ask for $Q_{p k I}=k_{I}^{\prime}$, $Q_{p k l I}=k_{I I}^{\prime}$ and $Q_{p k a b}=k^{\prime \prime}$. Based on Eq. (8), Eq.(9), and Eq. (10), $k, k_{I}^{\prime}, k_{I I}^{\prime}$ and $k^{\prime \prime}$ can be calculated, as listed in Table 4.

Table 4 Comparison list of all kinds of quality levels and $k, k_{I}^{\prime}, k_{I I}^{\prime}$ and $k^{\prime \prime}$

\begin{tabular}{|c|c|c|c|c|}
\hline $\begin{array}{c}\text { Quality } \\
\text { level }\end{array}$ & $k$ & $k_{I}^{\prime}$ & $k_{I I}^{\prime}$ & $k^{\prime \prime}$ \\
\hline 6-Sigma & 6.000 & 6.123 & 6.169 & 6.447 \\
\hline 5-Sigma & 5.000 & 5.154 & 5.211 & 5.548 \\
\hline 4-Sigma & 4.000 & 4.202 & 4.275 & 4.699 \\
\hline 3-Sigma & 3.000 & 3.285 & 3.385 & 3.936 \\
\hline
\end{tabular}

\subsection{Manufacturing scheduling performance indices}

Concerning manufacturing scheduling, since the electric scooter water-cooling green motor assembly consists of the inner water case underline process $(a=I)$ and the outer water case bore process $(a=I I)$, this paper supposes that random variable $T_{a}$ represents the manufacturing scheduling distribution of these 2 processes, a normal distribution of mean $u_{T a}$ and variable $\sigma_{T a}^{2}$, namely $T_{a} \sim N\left(u_{T a}, \sigma_{T a}^{2}\right)$. According to the theory of Chen and Huang (2006), the speed of manufacturing scheduling will affect the production quality, so manufacturing scheduling must be moderate. 
However, we usually ask for good manufacturing quality first and favorable manufacturing performance second. Under the premise of asking for good manufacturing quality, manufacturing scheduling definitely cannot be too fast, and it will be fine as long as the upper limit of the manufacturing scheduling is regulated. Therefore, this paper lets $U_{T a}$ represent the upper limit of manufacturing scheduling, so that it can modify the smaller-the-better six sigma quality indices proposed by Chen et al. (2017) as the manufacturing scheduling performance indices as below:

$$
Q_{T a}=\frac{U_{T a}-\mu_{T a}}{\sigma_{T a}}, a=I, I I
$$

Obviously, the relationship between the manufacturing scheduling performance indices and the manufacturing scheduling pass rate $p_{T a}$ is as follows:

$$
p_{T a}=p\left(T_{a}<U_{T a}\right)=\Phi\left(Q_{T a}\right)
$$

In other words, there is a one-on-one mathematical relationship between the manufacturing scheduling performance indices and the manufacturing scheduling pass rate $p_{T a}$. 


\section{Interval estimations of manufacturing performance indices}

As mentioned above, manufacturing performance indices include six sigma quality indices and manufacturing scheduling performance indices. Due to inevitable sampling errors in samples, the reliability of point estimates is still uncertain. If the point estimates are used to judge the quality level, that may lead to misjudgment. In view of this, many researchers, such as Kanichukattu and Luke (2013), and Chen et al. (2017), used the method of confidence intervals to evaluate the process quality, in order to lower down the chance of misjudgment. Consequently, this paper then induces the confidence intervals of these 2 manufacturing indices. Meanwhile, the confidence intervals are used to conduct evaluations and tests for performance indices, and results are sorted to build a manufacturing performance evaluation chart for the electric scooter green motor assembly.

\subsection{The confidence intervals of six sigma quality indices}

$$
\text { Suppose } Y_{a b 1}, \ldots, Y_{a b j}, \ldots, Y_{a b n} \text { is a set of random samples converted by variables, }
$$

whose sample mean and sample standard deviation are seen as follows:

$$
\bar{Y}_{a b}=\frac{1}{n} \times \sum_{j=1}^{n} X_{a b j} \sim N\left(\mu_{a b}, \frac{\sigma_{a b}^{2}}{n}\right) \text { and } S_{a b}=\sqrt{\frac{1}{n-1} \sum_{j=1}^{n}\left(Y_{a b j}-\bar{Y}_{a b}\right)^{2}} \text {. }
$$

Thus, the estimator of six sigma quality indices is shown as follows: 


$$
\hat{Q}_{p k a b}=\operatorname{Min}\left\{\hat{Q}_{p 1 a b}, \hat{Q}_{p 2 a b}\right\}
$$

where

$$
\hat{Q}_{p 1 a b}=\frac{1-\bar{Y}_{a b}}{S_{a b}}+1.5 \text { and } \hat{Q}_{p 2 a b}=\frac{1+\bar{Y}_{a b}}{S_{a b}}+1.5
$$

Under the assumption of normality, the following random variables,

$$
\begin{aligned}
& Z_{i}=\sqrt{n} \times(-1)^{i}\left[\left(\hat{Q}_{\text {piab }}-1.5\right)\left(\frac{S_{a b}}{\sigma_{a b}}\right)-\left(Q_{\text {piab }}-1.5\right)\right], i=1,2 \text { and } \\
& K_{a b}=\frac{(n-1) \times S_{a b}^{2}}{\sigma_{a b}^{2}}
\end{aligned}
$$

are mutually independently distributed as $N(0,1)$ and $\chi_{n-1}^{2}$, respectively.

Obviously, let $\alpha_{i}^{\prime}=1-\sqrt{1-\alpha_{i}}$, then

$$
\begin{aligned}
& P\left\{-z_{\alpha_{i}^{\prime} / 2} \leq N(0,1) \leq z_{\alpha_{i}^{\prime} / 2}, \chi_{\alpha_{i}^{\prime} / 2, n-1}^{2} \leq \chi_{n-1}^{2} \leq \chi_{1-\alpha_{i}^{\prime} / 2, n-1}^{2}\right\}=1-\alpha_{i} \\
& \Rightarrow P\left\{L Q_{\text {piab }} \leq Q_{\text {piab }} \leq U Q_{\text {piab }}\right\} \geq 1-\alpha_{i}, \text { where } \\
& L Q_{\text {piab }}=\left(\hat{Q}_{\text {piab }}-1.5\right) \sqrt{\frac{\chi_{\alpha_{\alpha^{\prime}} / 2, n-1}^{2}}{n-1}}-\frac{z_{\alpha_{i}^{\prime} / 2}}{\sqrt{n}}+1.5 \\
& U Q_{\text {piab }}=\left(\hat{Q}_{\text {piab }}-1.5\right) \sqrt{\frac{\chi_{1-\alpha_{i}^{\prime} / 2, n-1}^{2}}{n-1}}+\frac{z_{\alpha_{i}^{\prime} / 2}}{\sqrt{n}}+1.5
\end{aligned}
$$

$z_{\alpha_{i}^{\prime} / 2}$ is the upper $\alpha_{i}^{\prime} / 2$ quantile of $N(0,1)$ and $\chi_{\alpha_{i}^{\prime} / 2, n-1}^{2}$ is the lower $\alpha_{i}^{\prime} / 2$ quantile of the chi-square distribution with $n-1$ degrees of freedom. Let $A_{i}=\left\{L Q_{\text {piab }} \leq Q_{\text {piab }} \leq U Q_{\text {piab }}\right\}, i=1,2$ then $P\left(A_{i}\right)=1-\alpha_{i}$ and $P\left(A_{i}^{c}\right)=\alpha_{i}$. Based on De Morgan theorem and Boole's inequality, we have 


$$
\begin{aligned}
& P\left(A_{1} \cap A_{2}\right) \geq 1-P\left(A_{1}^{c}\right)-P\left(A_{2}^{C}\right)=1-\left(\alpha_{1}+\alpha_{2}\right), \text { that is } \\
& P\left\{L Q_{p 1 a b} \leq Q_{p 1 a b} \leq U Q_{p 1 a b}, L Q_{p 2 a b} \leq Q_{p 2 a b} \leq U Q_{p 2 a b}\right\} \geq 1-\left(\alpha_{1}+\alpha_{2}\right) \\
& \Rightarrow P\left\{\operatorname{Min}\left(L Q_{p 1 a b}, L Q_{p 2 a b}\right) \leq \operatorname{Min}\left(Q_{p 1 a b}, Q_{p 2 a b}\right) \leq \operatorname{Min}\left(U Q_{p 1 a b}, U Q_{p 2 a b}\right)\right\} \geq 1-\alpha \\
& \Rightarrow P\left\{L Q_{p k a b} \leq Q_{p k a b} \leq U Q_{p k a b}\right\} \geq 1-\alpha, \text { where } \alpha=\alpha_{1}+\alpha_{2}, \\
& L Q_{p k a b}=\operatorname{Min}\left(L Q_{p 1 a b}, L Q_{p 2 a b}\right) \text { and } U Q_{p k a b}=\operatorname{Min}\left(U Q_{p 1 a b}, U Q_{p 2 a b}\right) .
\end{aligned}
$$

Obviously, $\left[L Q_{p k a b}, U Q_{p k a b}\right]$ is the $100(1-\alpha) \%$ confidence intervals of the six sigma quality index $Q_{p k a b}$.

\subsection{The confidence intervals of $Q_{T a}$}

Manufacturing scheduling sample data are resulted from the random sampling of the process. Because the electric scooter motor assembly comprises 2 processes - the inner water case underline process $(\mathrm{a}=\mathrm{I})$ and the outer water case bore process $(\mathrm{a}=$ II), this paper selects 2 sets of random samples, $T_{a 1}, T_{a 2}, \ldots, T_{n a}, \mathrm{a}=\mathrm{I}, \mathrm{II}$, drawn from the distribution of these 2 processes $N\left(u_{T a}, \sigma_{T a}^{2}\right)$, whose sample mean and sample standard deviation are displayed as follows:

$$
\bar{T}_{a}=\frac{1}{n} \times \sum_{j=1}^{n} T_{a j} \sim N\left(\mu_{T a}, \frac{\sigma_{T a}^{2}}{n}\right) \text { and } S_{T a}=\sqrt{\frac{1}{n-1} \sum_{j=1}^{n}\left(T_{a j}-\bar{T}_{a}\right)^{2}} .
$$

Therefor, the estimator of six sigma quality indices is shown as follows: 


$$
\hat{Q}_{T a}=\frac{U_{T a}-\bar{T}_{a}}{S_{T a}}, a=I, I I
$$

Similarly to six sigma quality indices, under the assumption of normality, the

following random variables,

$$
Z=\sqrt{n} \times\left[Q_{T a}-\hat{Q}_{T a} \times\left(\frac{S_{a b}}{\sigma_{a b}}\right)\right] \text { and } K_{a}=\frac{(n-1) \times S_{T a}^{2}}{\sigma_{T a}^{2}}
$$

are mutually independently distributed as $N(0,1)$ and $\chi_{n-1}^{2}$, respectively.

Let $\alpha^{\prime}=1-\sqrt{1-\alpha}$, then

$$
\begin{aligned}
& P\left\{-z_{\alpha^{\prime} / 2} \leq N(0,1) \leq z_{\alpha^{\prime} / 2}, \chi_{\alpha^{\prime} / 2, n-1}^{2} \leq \chi_{n-1}^{2} \leq \chi_{1-\alpha^{\prime} / 2, n-1}^{2}\right\}=1-\alpha \\
& \Rightarrow P\left\{L Q_{T a} \leq Q_{T a} \leq U Q_{T a}\right\} \geq 1-\alpha, \text { where } \\
& L Q_{T a}=\hat{Q}_{T a} \times \sqrt{\frac{\chi_{\alpha^{\prime} / 2, n-1}^{2}}{n-1}}-\frac{z_{\alpha^{\prime} / 2}}{\sqrt{n}} \\
& U Q_{T a}=\hat{Q}_{T a} \times \sqrt{\frac{\chi_{1-\alpha^{\prime} / 2, n-1}^{2}}{n-1}}+\frac{z_{\alpha^{\prime} / 2}}{\sqrt{n}}
\end{aligned}
$$

$z_{\alpha^{\prime} / 2}$ is the upper $\alpha^{\prime} / 2$ quantile of $N(0,1)$ and $\chi_{\alpha^{\prime} / 2, n-1}^{2}$ is the lower $\alpha^{\prime} / 2$

quantile of the chi-square distribution with $n-1$ degrees of freedom. Obviously, $\left[L Q_{T a}, U Q_{T a}\right]$ is the $100(1-\alpha) \%$ confidence intervals of $Q_{T a}$.

\subsection{Manufacturing performance evaluation chart}

In the previous 2 sections, the confidence intervals between 2 manufacturing scheduling performance indices and 9 six sigma quality indices have been induced. 
Next, the confidence intervals can be applied to performance evaluations as well as tests. If the process quality level of the motor assembly is set as $k \sigma$, then the process quality level required value $k^{\prime \prime} \sigma$ can be derived from Table 2, corresponding to the 9 important quality characteristics.

1. When $k^{\prime \prime}<L Q_{\text {pkab }}$, then it is concluded that the quality level is insufficient and needs to improve, so it is labeled as "Bad".

2. When $L Q_{p k a b} \leq k^{\prime \prime} \leq U Q_{p k a b}$, then it is concluded that the quality level meets the requirements, so it is labeled as "Okay".

3. When $U Q_{p k a b}>k^{\prime \prime}$, then it is concluded that the quality level exceeds the requirements, so it is labeled as "Good".

4. When the $1^{\text {st }}$ item to the $5^{\text {th }}$ item are all labeled as "Okay" or "Good", then it comes to the conclusion that the quality level of the inner water case underline process meets the requirements. As long as 1 item is labeled as "Bad", then it comes to the conclusion that the quality level of the inner water case underline process does not meet the requirements and needs to improve.

5. When the $6^{\text {th }}$ item to the $9^{\text {th }}$ item are all labeled as "Okay" or "Good", then it comes to the conclusion that the quality level of the outer water case bore process meets the requirements. As long as 1 item is labeled as "Bad", then it 
comes to the conclusion that the quality level of the outer water case bore process does not meet the requirements and needs to improve.

6. When the $1^{\text {st }}$ item to the $9^{\text {th }}$ item are all labeled as "Okay" or "Good", then it comes to the conclusion that the quality level of the electric scooter motor assembly meets the requirements. As long as 1 item is labeled as "Bad", then it comes to the conclusion that the quality level of the electric scooter motor assembly does not meet the requirements and needs to improve.

Similarly, if the manufacturing scheduling performance of these 2 processes is set as $Q_{T a}=v_{a}$, then the evaluation criteria of the manufacturing scheduling performance are described as follows:

1. When $v_{a}<L Q_{T a}$, then it is concluded that the manufacturing scheduling performance of the $a^{\text {th }}$ process is not good and needs to improve, so it is labeled as "Bad".

2. When $L Q_{T a} \leq v_{a} \leq U Q_{T a}$, then it is concluded that the manufacturing scheduling performance of the $a^{\text {th }}$ process meets the requirements, so it is labeled as "Okay".

3. When $v_{a}>U Q_{T a}$, then it is concluded that the manufacturing scheduling performance of the $a^{\text {th }}$ process is good, so it is labeled as "Good". 
4. When 2 items are both labeled as "Okay" or "Good", then it comes to the conclusion that the manufacturing scheduling performance of the electric scooter motor assembly is good. As long as 1 item is labeled as "Bad", then it comes to the conclusion that the manufacturing scheduling performance of the electric scooter motor assembly does not meet the requirements and needs to improve.

Subsequently, according to the abovementioned manufacturing performance evaluation criteria of the 2 processes for the electric scooter motor assembly, the required information for these two evaluation criteria is collected and calculated, compacted in Table 5. Then, based on the manufacturing performance evaluation criteria of the 2 processes, evaluations will be made.

Accordingly, this study adopts a real case to explain the application of manufacturing performance evaluation indices. The product quality of the case-study company are requested to reach 5 sigma $(k=5)$; thus, based on Eqs. (8)-(10), the quality level of the inner water case underline process, $5.154\left(k_{I}^{\prime}=5.154\right)$, that of the outer water case bore process, $5.211\left(k_{I I}^{\prime}=5.211\right)$, and that of all individual important quality characteristics, $5.548\left(k^{\prime \prime}=5.548\right)$, can be computed. Next, this study selects 30 sets $(n=30)$ of sampling data, calculates the parameters related to the mean of samples ( $\bar{X}$ ) and sigma (s), and applies them to Eqs. (13)-(14), so that the confidence 
intervals of six sigma evaluation indices for the related processes can be obtained, as displayed in Table 5. Furthermore, concerning the part of manufacturing scheduling performance evaluation, based on the procedures of the flow in section 4.2 and Eqs. (16)-(17), the confidence intervals of the related manufacturing scheduling performance indices can be received, as shown in Table 5.

Table 5 Manufacturing performance evaluation chart for the electric scooter green motor assembly

\begin{tabular}{|c|c|c|c|c|}
\hline \multirow{2}{*}{ Quality Characteristics } & \multicolumn{2}{|c|}{ Process level performance } & \multicolumn{2}{|c|}{$\begin{array}{c}\text { Manufacturing scheduling } \\
\text { performance }\end{array}$} \\
\hline & $\begin{array}{l}\text { Confidence } \\
\text { Intervals }\end{array}$ & Remarks & $\begin{array}{l}\text { Confidence } \\
\text { Intervals }\end{array}$ & Remarks \\
\hline $\begin{array}{l}I . \text { Inner water case } \\
\text { underline process }\end{array}$ & $L \hat{Q}_{p k l} \leq 5.154 \leq U \hat{Q}_{p k I}$ & "Okay" & \multirow{6}{*}{$L \hat{Q}_{T I} \leq 70 \leq U \hat{Q}_{T I}$} & “Okay" \\
\hline $\begin{array}{l}\text { 1. Motor front cover } \\
\text { height }\end{array}$ & $U \hat{Q}_{p k I 1}>5.548$ & "Good" & & “Good” \\
\hline $\begin{array}{l}\text { 2. Motor front cover } \\
\text { circle diameter }\end{array}$ & $U \hat{Q}_{p k I 2}>5.548$ & "Good" & & “Okay” \\
\hline $\begin{array}{l}\text { 3. Motor front cover } \\
\text { locking hole center }\end{array}$ & $L \hat{Q}_{p k l 3} \leq 5.548 \leq U \hat{Q}_{p k l 3}$ & "Okay" & & “Okay” \\
\hline $\begin{array}{l}\text { 4. Bearing circle } \\
\text { diameter }\end{array}$ & $L \hat{Q}_{p k l 4} \leq 5.548 \leq U \hat{Q}_{p k I 4}$ & "Okay" & & "Okay" \\
\hline 5. Bearing depth & $L \hat{Q}_{p k 5} \leq 5.548 \leq U \hat{Q}_{p k L 5}$ & "Good" & & "Good" \\
\hline $\begin{array}{l}\text { II. Outer water case } \\
\text { bore process }\end{array}$ & $L \hat{Q}_{p k l I} \leq 5.211 \leq U \hat{Q}_{p k I I}$ & "Bad" & \multirow{5}{*}{$L \hat{Q}_{T I I}<65$} & "Bad" \\
\hline $\begin{array}{l}\text { 1. Small motor cover } \\
\text { circle diameter }\end{array}$ & $L \hat{Q}_{p k I I 1} \leq 5.548 \leq U \hat{Q}_{p k I I 1}$ & "Okay" & & "Bad" \\
\hline $\begin{array}{l}\text { 2. Motor rotor circle } \\
\text { diameter }\end{array}$ & $L \hat{Q}_{p k I I 2}<5.548$ & "Bad" & & "Bad" \\
\hline $\begin{array}{l}\text { 3. Body engagement } \\
\text { hole circle diameter }\end{array}$ & $L \hat{Q}_{p k l I 3} \leq 5.548 \leq U \hat{Q}_{p k l I 3}$ & “Okay" & & "Bad" \\
\hline $\begin{array}{l}\text { 4. Body engagement } \\
\text { hole center }\end{array}$ & $U \hat{Q}_{p k I I 4}>5.548$ & "Good" & & "Bad" \\
\hline
\end{tabular}


Next, this study can be based on the manufacturing performance evaluation criteria in section 4.3 to make judgments. Concerning the quality level of the inner water case underline process, its process level is marked "Okay", and the process levels of its five important quality characteristics are marked as "Okay" or "Good", showing that the process quality level and the manufacturing scheduling both meet the requirements. In addition, as to the quality level of the outer water case bore process, its process level is marked "Bad", and among the processes of its four important quality characteristics, the motor rotor circle diameter is marked as "Bad" as well, indicating that the process quality level and the manufacturing scheduling both do not meet the requirements and need to improve.

\section{Process quality analysis and improvement model}

According to the abovementioned manufacturing performance evaluation chart, it was discovered that the critical factor which led to ill performance of the electric scooter green motor assembly process was the motor rotor circle diameter, whose process capability and manufacturing scheduling both failed, so the process should be reviewed and improved. Therefore, this study will employ the characteristic cause-and-effect diagram and the Taguchi method to figure out the best parameter 
matching, and finally use the control chart to ensure the effect of improvement, as stated separately below.

\subsection{Characteristic cause-and-effect diagram analysis}

At present, there are plenty of tools for process performance analyses, such as Brain Storming which can create visualization as a start, Affinity Diagramming, and Structure Tree / Tree Diagram, which can help people systemize to categorize their visualization and selections. The high-level flow chart, SIPOC (read as sye-pahk) Diagram, and the Flowchart/ Process Map are employed to indicate the details of importance processes. Meanwhile, the Cause-and-Effect diagram or Fishbone diagram is used to figure out the possible causes of the problems and categorize them, so that other causes seem to be linked together in the structure tree to clarify the important processes or problems.

According to K. Srinivasan (2014), the characteristic cause-and-effect diagram proposed by Professor Kaoru Ishikawa in 1976 is often used as an important tool for problem analyses as well as widely applied to the promotion of quality activities. Thus, the characteristic cause-and-effect diagram (see Fig. 3) is employed in this study to analyze the reasons for the ill process performance of motor rotor circle diameter, and it is also seen as a basis to find out all factors which lead to the ill process performance of motor rotor circle diameter. 


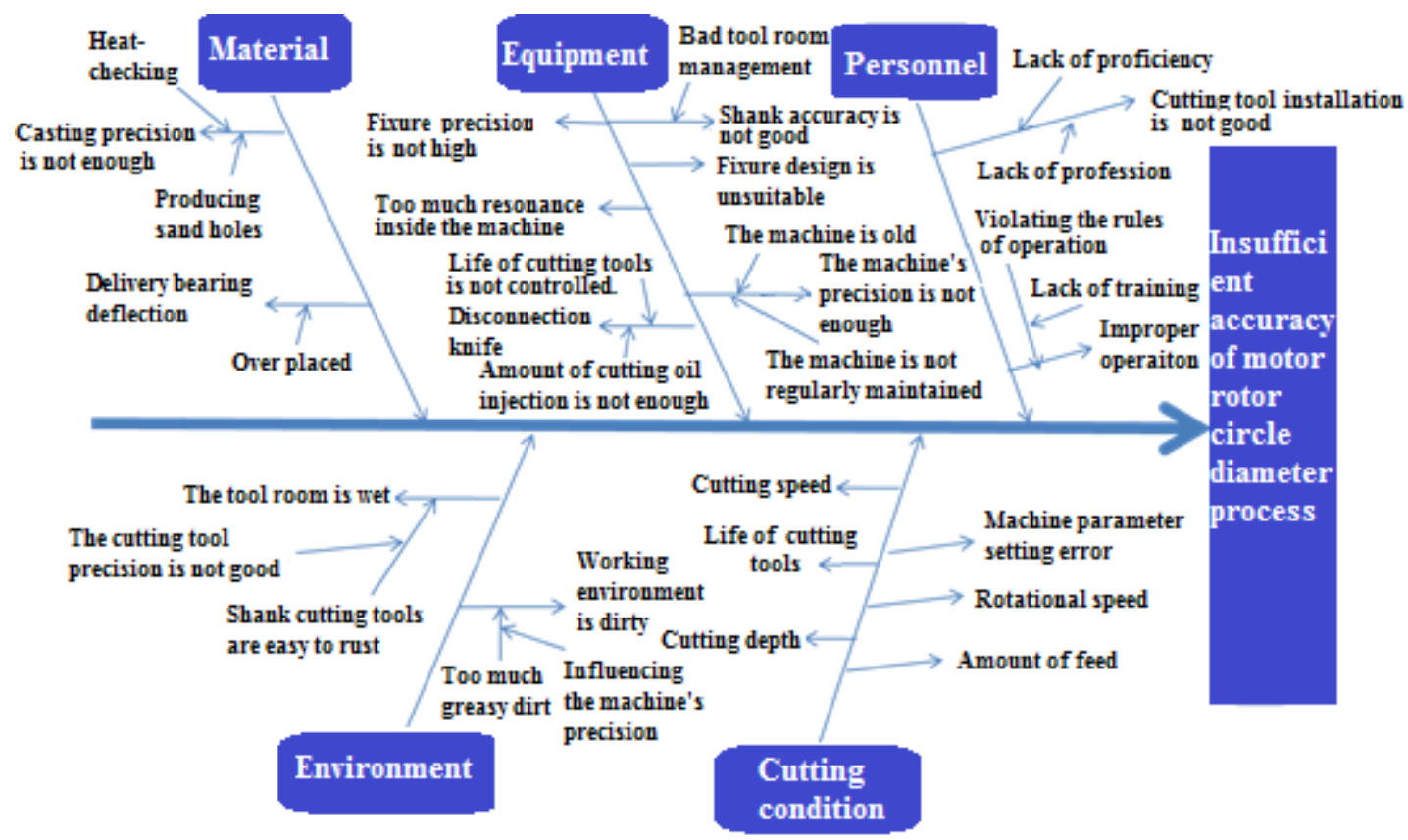

Fig. 3 Characteristic cause-and-effect diagram of the ill process performance of motor rotor circle diameter

After discussing with the factory engineers and experts, this study discovered that the critical factor (see Fig. 3) which caused the ill process performance of motor rotor circle diameter was mainly resulted from the problem of cutting conditions in the process capability, and other important influential factors were cutting depth, cutting speed, amount of feed, and rotational speed. This study employed the Taguchi method commonly seen in the industry to figure out the best parameters to improve the accuracy of the motor rotor circle diameter process and then to enhance the entire yield and quality of the motor process. In addition, the reason that caused ill manufacturing scheduling was the tool room management. 
When the cutting condition in the process of the motor rotor's circle diameter is not good or there is something wrong with the cutting tool room management, it will affect the green motor operation performance and even lead to ill air-tightness of the outer water case. Thus, the effect of the motor water-cooling system will be influenced, and the problem of carbon emission will arise to affect our environment, so that the performance achievement of the environmental and social responsibilities in TBL will decline.

\subsection{Taguchi method}

Ross (1988), Taguchi (1991) and Chen et al. (2006) stated that the Taguchi method proposed by a Japanese doctor named Taguchi Genichi in the 1950s determined the best parameter with an empirical method. Besides, product design and quality robustness are provided with the lowest cost and the minimum experimental times within a short period of time. Hence, to receive the best parameter settings, this study used the Taguchi method to carry out analyses and improvement of process quality. 
Table 6 Control factor level list of the motor rotor circle diameter process

\begin{tabular}{|l|c|c|c|}
\hline & Level 1 & Level 2 & Level 3 \\
\hline A Cutting depth $(\mathrm{mm})$ & 0.2 & 0.25 & 0.3 \\
\hline B Cutting speed (m/min) & 250 & 280 & 320 \\
\hline C Amount of feed (mm/rpm) & 0.1 & 0.15 & 0.2 \\
\hline D Rotational speed (rpm) & 800 & 1300 & 2000 \\
\hline
\end{tabular}

After discussing with the experts and factory engineers, it was found that cutting depth, cutting speed, amount of feed and rotational speed were the core control factors which affected the imprecision of motor rotor circle diameter process. Additionally, each control factor has 3 levels listed in the control factor level list of motor rotor circle diameter process, as displayed in Table 6, and the Taguchi method is adopted to find out the best parameters for 4 factors and 3 levels, with the degree of freedom -8 . Therefore, this study adopts the $L_{9}\left(3^{4}\right)$ orthogonal array to repeat experiments 3 times. According to Taguchi (1987) and Taguchi (1991), the $L_{9}\left(3^{4}\right)$ orthogonal array is an orthogonal array highly recommended by Dr. Taguchi, and its experimental results are also presented in Table 7. 
Table 7 List of $L_{9}\left(3^{4}\right)$ orthogonal array experimental results

\begin{tabular}{|c|c|c|c|c|c|c|c|c|}
\hline \multirow{2}{*}{ Experiment Number } & \multicolumn{4}{|c|}{ Parameters and Levels } & \multicolumn{4}{c|}{ Result } \\
\cline { 2 - 9 } & A & B & C & D & $Y_{1}$ & $Y_{2}$ & $Y_{3}$ & S/N \\
\hline 1 & 0.2 & 250 & 0.1 & 800 & 96.0215 & 96.0238 & 96.0227 & 98.43078 \\
\hline 2 & 0.2 & 280 & 0.15 & 1300 & 96.01802 & 96.01793 & 96.01814 & 119.1938 \\
\hline 3 & 0.2 & 320 & 0.2 & 2000 & 95.9763 & 95.9883 & 95.9867 & 83.36484 \\
\hline 4 & 0.25 & 250 & 0.15 & 2000 & 95.9897 & 95.9884 & 95.9871 & 97.36551 \\
\hline 5 & 0.25 & 280 & 0.2 & 800 & 96.019 & 96.0189 & 96.0194 & 111.1962 \\
\hline 6 & 0.25 & 320 & 0.1 & 1300 & 96.009 & 96.0084 & 96.012 & 93.94088 \\
\hline 7 & 0.3 & 250 & 0.2 & 1300 & 95.9947 & 95.9856 & 95.9971 & 83.98587 \\
\hline 8 & 0.3 & 280 & 0.1 & 2000 & 96.0118 & 96.0123 & 96.0109 & 102.6279 \\
\hline 9 & 0.3 & 320 & 0.15 & 800 & 96.0196 & 96.0191 & 96.0194 & 111.6309 \\
\hline
\end{tabular}

According to Taguchi (1987) and Taguchi (1991), $\mathrm{S} / \mathrm{N}$ is the short form of signal to noise. If $\mathrm{S} / \mathrm{N}$ is larger, it means signal is larger than noise, so that it will be easy to judge whether the received result is signal or noise. As a result, when the ratio of $\mathrm{S} / \mathrm{N}$ of the motor rotor circle diameter process for the green electric scooter motor is larger, the precision is better. In addition, the motor rotor circle diameter for the green electric scooter motor is of the normal quality characteristic in this study. Its equation is listed as follows:

$$
S / N=10 \log \left(\frac{S_{m}-V_{e}}{n V_{e}}\right)
$$


Through the $L_{9}\left(3^{4}\right)$ orthogonal array experiments of Table 6 and Eq. (18), the ratio of $\mathrm{S} / \mathrm{N}$ for each experiment can be received. When the ratio of $\mathrm{S} / \mathrm{N}$ is larger, it means the precision is better and also reveals that the quality of the green electric scooter motor's motor rotor circle diameter process is better. Finally, this study adopts the $\mathrm{S} / \mathrm{N}$ ratios listed in Table 6 and receives the mean of $\mathrm{S} / \mathrm{N}$ ratios of each level in the 4 factors. Then, these data will be drawn in Fig. 4 to obtain the best parameter settings: A. cutting speed $(0.25 \mathrm{~mm})$, B. cutting speed $(280 \mathrm{~m} / \mathrm{min})$, C. amount of feed $(0.15 \mathrm{~mm} / \mathrm{rpm})$, and $\mathrm{D}$. rotational speed. In the future, these best parameter settings will be regarded as the standards of settings, to maintain the stability of process quality and then to boost the process yield rate.

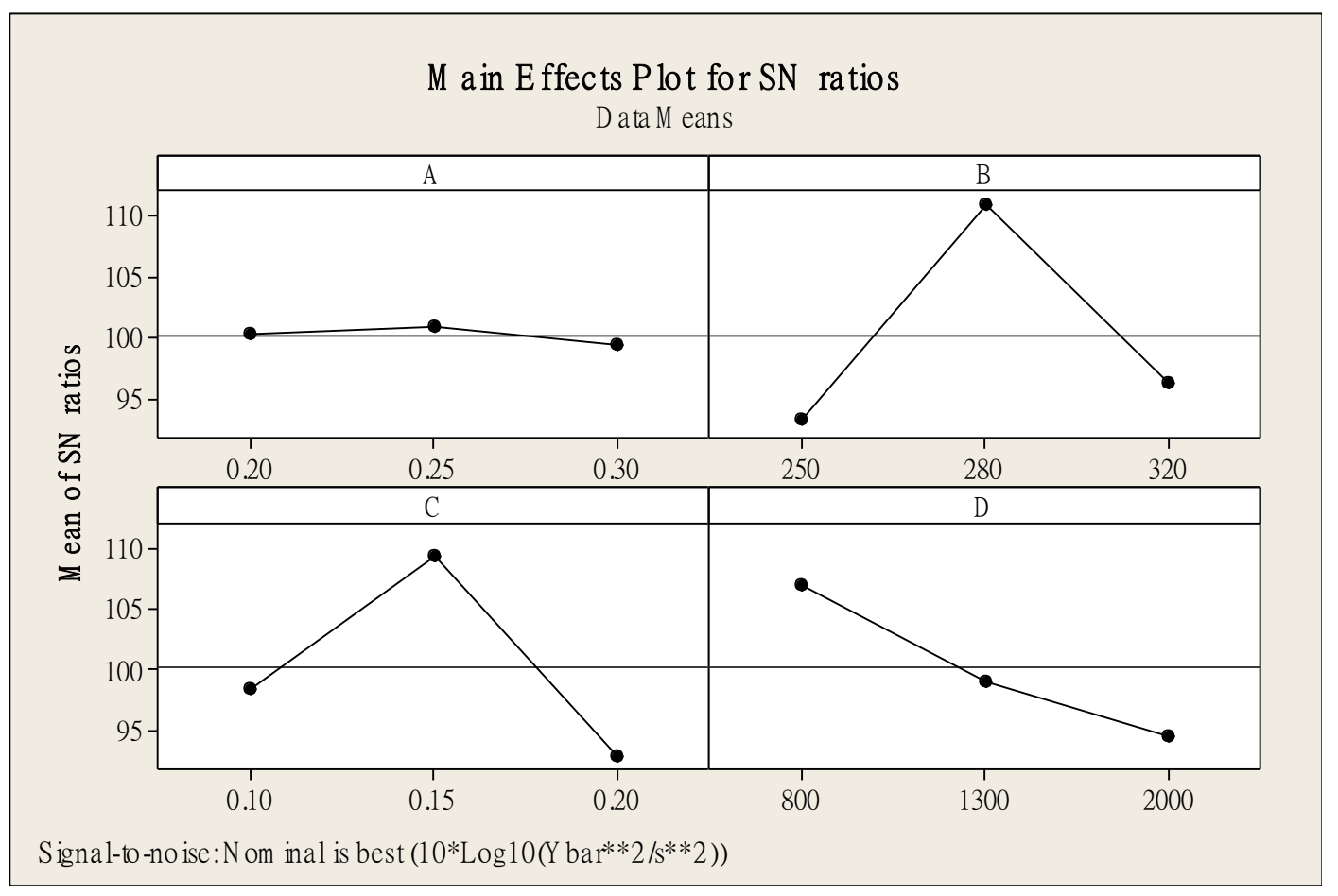

Fig. 4 Cause-and-effect diagram of $\mathrm{S} / \mathrm{N}$ ratios 


\subsection{Improvement of the tool room management}

The production model of the case-study manufacturer is the model of small-volume large-variety production. As to the applied cutting tools, there were excessive numbers of hilts and shanks, so that caused some difficulty in the tool room management. Good tool room management can not only reduce the waste but also cut the cost. Therefore, the tool room management is an important factor of maintaining the process yield. After discussing the factory's management and on-site engineers and observing the ill factors of the tool room management shown in the cause-and-effect diagram (see Fig. 5), it was learned that the case-study manufacturer's lack of a set of regulation flow related to the tool room management was the factor which led to bad tool room management. Thus, this study based on the current situation improves and regulates the SOP of tool management in the control stage for better management.

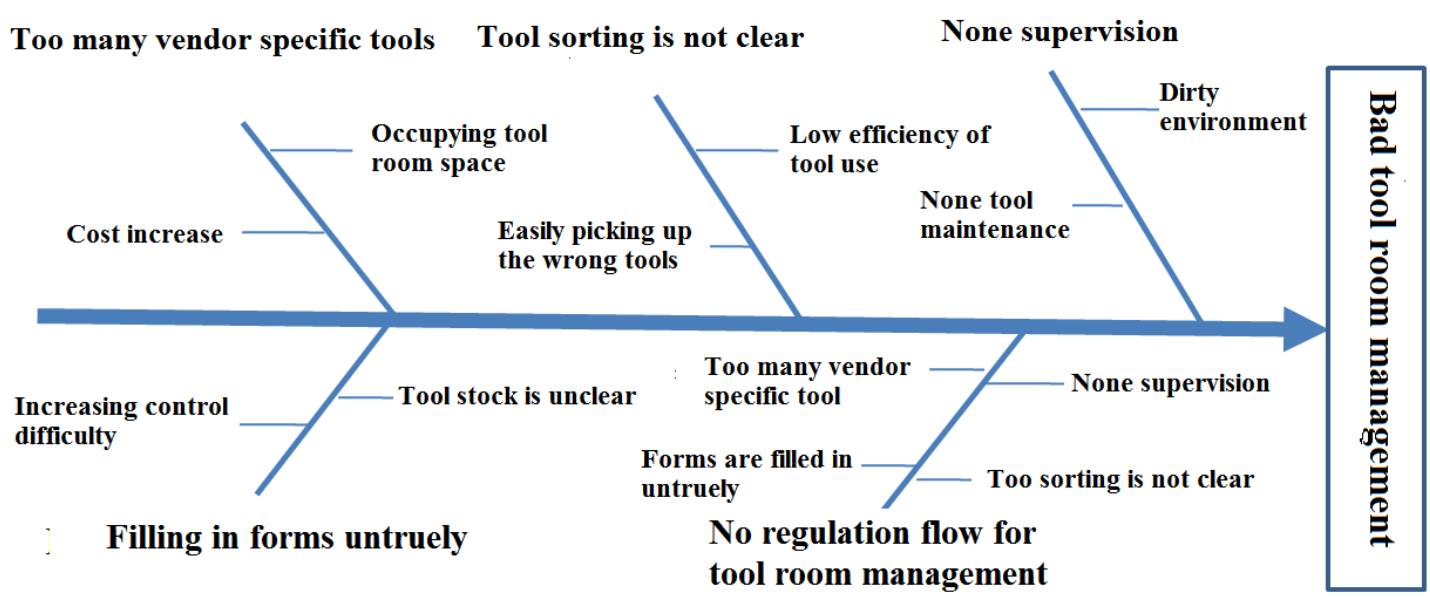

Fig. 5 Characteristic cause-and effect diagram for bad tool room management 


\section{$5.4 \bar{X}-R$ chart of control verifying the improvement outcomes}

After the motor rotor circle diameter process parameters of the electric scooter green motor and tool room management are improved, this study extracts 20 sets of sampling data in the static process which has been reset. Each set has 5 samples, and the Minitab 16 software is used to draw the Xbar-R Chart of control, as seen in Fig. 6. It is obviously seen that both the accuracy and precision of these 20 sets of samples are within the control range of the new process, indicating that the process is static, so it can be used as a monitoring tool for the motor rotor circle diameter process in the future.

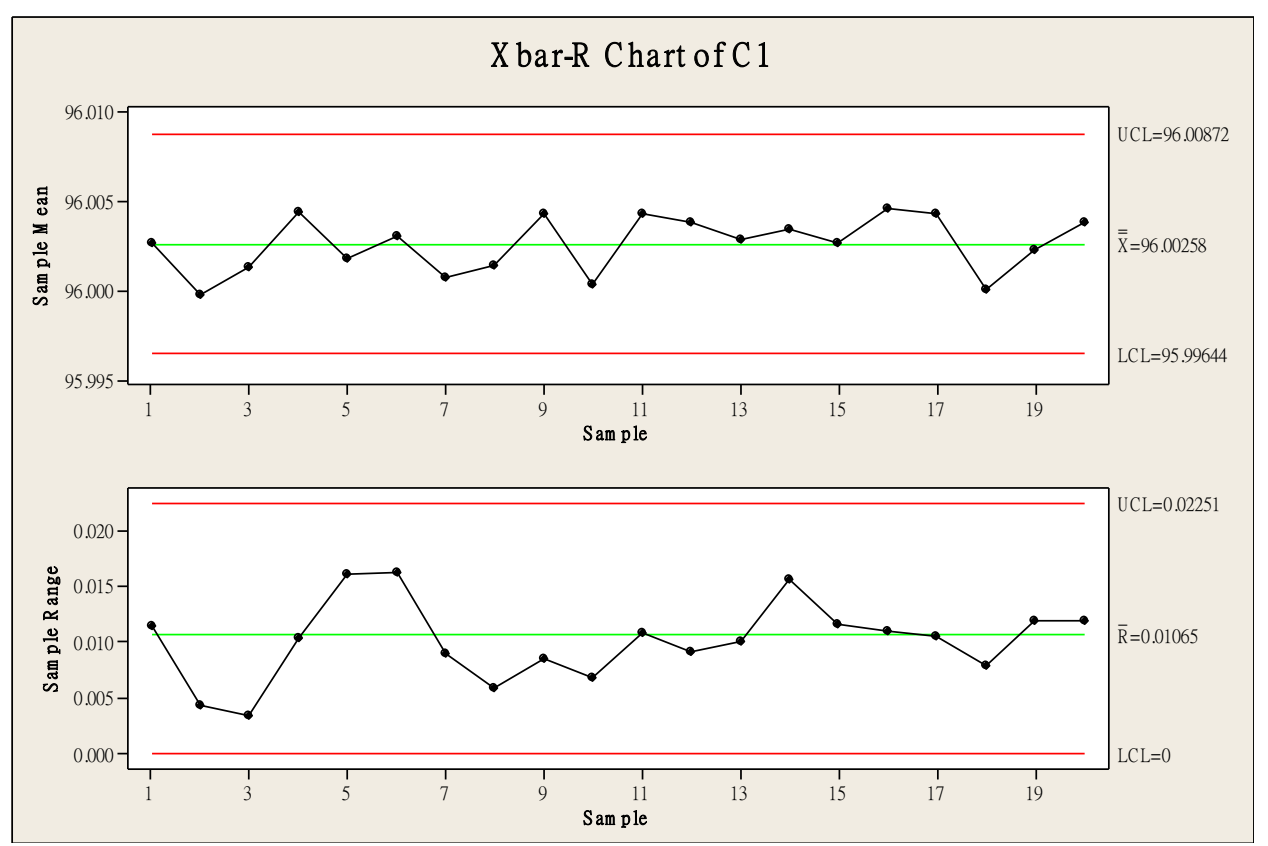

Fig. $6 \bar{X}-R$ chart of control after improvement 
To sum up, this study applies Lean Six Sigma to the industry related to green energy. The process of analysis, improvement, and control can enhance the product quality, decrease the rates of process scrap and Reduce, increase the rates of product availability and maintenance and Reuse, and raise the rate of Recycle for all spare parts. At the same time, owing to the increase of lifetime, the time of Recovery is postponed. Consequently, Lean Six Sigma not only can reach the goal of economic benefits of promoting the process quality performance but also can respond to the policy of energy saving and carbon reduction and facilitate the Triple Bottom Line (TBL), in order to help enterprises head to the sustainable development of ecological and social benefits.

\section{Conclusions}

With the continually rapid growth of research, development, and manufacturing technology, humans' consuming habits are apparently changed and influenced, and modern consumers tend to emphasize quality and efficiency more and more. Thus, enterprises must provide various, environmentally friendly, and high-quality products to satisfy customers' demands and to maintain enterprises' sustainable development. However, attempting to reach the goal of sustainable development, enterprises must 
rebuild or improve by means of the internal process to create added value. Lean Six

Sigma possesses the advantages of speeding up the process and conducting the systematic statistics analyses, so that it is a popular process management tool which can help enterprises create added value and reach the goal of sustainable development. Therefore, this paper adopted "the process performance of the electric scooter water-cooling motor assembly" as a case study, applied the process and idea of Lean Six Sigma, and developed a set of process performance evaluation and improvement model for the electric scooter water-cooling motor assembly, in order to reach the goals of shortening manufacturing scheduling time and lowering the process variation with Lean Six Sigma.

Firstly, this study integrated VOC with VSM to figure out the non-value manufacturing scheduling and quality level and solve the problems immediately. Next, 2 important processes of the motor assembly were discussed and 9 important quality characteristics were sorted out. In the light of manufacturing scheduling and process quality, manufacturing scheduling indices and six sigma quality evaluation indices were respectively presented. Then, the confidence intervals corresponding to these two types of indices were concluded and were employed to conduct evaluations and tests of performance indices. Also, a manufacturing performance evaluation chart of the electric scooter motor assembly was formed. According to the abovementioned 
method, real samples and the performance evaluation chart were used to find out that the process of motor rotor circle diameter did not meet standards in both aspects manufacturing quality level and scheduling. The characteristic cause-and-effect diagram was employed to analyze and discover 4 items of control factors which can influence the process. The Taguchi method was used to find out 4 items of the best parameter settings: cutting depth $(0.25 \mathrm{~mm})$, cutting Speed $(280 \mathrm{~m} / \mathrm{min})$, amount of feed $(0.15 \mathrm{~mm} / \mathrm{rpm})$, and rotational speed $(800 \mathrm{rpm})$, in order to promote the process quality. Meanwhile, standard operation procedure was also imported to assist the tool room management inside the factory to ensure the enhancement of tool room management and process quality. Study results showed that the defect rate of the processed product decreased $5 \%$, the defect rate of the airtightness lowered down (decrease 4\%), and then the manufacturing efficiency was lifted to shorten the manufacturing time (estimated to lower $13 \%$ of time waste). This model constructed by this study is also applicable to other industries' process performance evaluations and improvement, aiming to reach the goals of shortening the manufacturing time and reducing the process variation with Lean Six Sigma.

Furthermore, this study applied the method of Lean Six Sigma to the issue related to green energy and promoted the performance of 3TBL/sustainable production. Since this study is of great value and importance in terms of sustainable 
development of green energy, it can supplement the insufficiency of literatures concerning sustainable improvement. In terms of management implications, due to the fact that the product of this study case must be manufactured with high process accuracy and timeliness, it is necessary to grasp product quality and resources through continuous improvement and immediate feedback in order to achieve the expected performance of water-cooling green motors. If Lean Six Sigma is not used, manufacturing costs may be wasted due to differences in manufacturing process and time, and product performance, so that the goal of $3 \mathrm{TBL} /$ sustainable production as well as the performance needed by the product cannot be achieved. Therefore, it is relatively important for this study to select the systematic approach, Lean Six Sigma, to reach the goal. In addition, this study has faced the following research limitations: (1) though this study applied Lean Six Sigma to the green motor, most of the restrictions focused on the issue of the process quality. This study suggests that the future researchers be able to select the cases which can accelerate the development of 3TBL/sustainable production. (2) When this study was collecting VOC, the content related to the environment and society seemed insufficient. Therefore, this study suggests that the future researchers be able to make further discussions on the VOC's impact on the environment and society, in order to obtain more complete applications and benefits of 3TBL. 


\section{References}

1. Almer C. \& Winkler R. (2017). Analyzing the effectiveness of international environmental policies: The case of the Kyoto Protocol. Journal of Environmental Economics and Management, 82, 125-151.

2. Alsyouf, I., Kumar, U., Al-Ashi, L., \& Al-Hammadi, M. (2018). Improving baggage flow in the baggage handling system at a UAE-based airline using lean Six Sigma tools. Quality Engineering. (In Press)

3. Andrew, T., Barton, R., \& Okafor, C. C. (2009). Applying lean six sigma in a small engineering company - a model for change. Manufacturing Technology Management, 20(1), 113-129.

4. Antony J., Rodgers B., \& Cudney E. A. (2017). Lean Six Sigma for public sector organizations: is it a myth or reality? International Journal of Quality \& Reliability Management, 34(9), 1402-1411.

5. Bellisario, A. \& Pavlov, A. (2018). Performance management practices in lean manufacturing organizations: a systematic review of research evidence. Production Planning \& Control, 29(5), 367-385.

6. Chen, M., \& Lyu, J. (2009). A Lean Six-Sigma approach to touch panel quality improvement. Production Planning and Control, 20(5), 445-454.

7. Cherrafi, A., Elfezazi, S., Govindan, K., Garza-Reyes, J. A., Benhida, K. \& Mokhlis, A. (2017). A framework for the integration of Green and Lean Six Sigma for superior sustainability performance. International Journal of Production Research, 55(15), 4481-4515.

8. Chen, K. S., Chen, H. T., \& Chang, T. C. (2017). The construction and application of Six Sigma quality indices. International Journal of Production Research, 55(8), 2365-2384.

9. Chen, K. S. \& Huang, M. L. (2006). Performance measurement for a manufacturing system based on quality, cost and time. International Journal of Production Research, 44(11), 101-123. 
10. Chen, K. S., Wang, C. H., \& Chen, H. T. (2006). A MAIC approach to TFT-LCD panel quality improvement", Microelectronics Reliability, 46(7), 1189-1198.

11. Chang, T. C., Wang, K. J., \& Chen, K. S. (2014). Sputtering process assessment of ITO film for multiple quality characteristics with one-sided and two-sided specifications. Journal of Testing and Evaluation, 42(1), 196-203.

12. Dejan C., Predrag S., Zoran M., Vukman B., Valentina T., Marina J. \& Biljana V. (2013). GHG (Greenhouse Gases) emission inventory and mitigation measures for public district heating plants in the Republic of Serbia. Journal of Energy, 57, 788-795.

13. Folster, S., \& Nystrom J. (2010). Climate Policy to Defeat the Green Paradox. A Journal of the Human Environment, 39, 223-235.

14. Garza-Reyes, J. A., Al-Balushi M., Antony, J. \& Kumar, V. (2016). A Lean Six Sigma framework for the reduction of ship loading commercial time in the iron ore pelletising industry. Production Planning \& Control, 27(13), 1092-1111.

15. Gupta, S. K., Antony, J., Lacher, F., \& Douglas J. (2018). Lean Six Sigma for reducing student dropouts in higher education - an exploratory study. Total Quality Management \& Business Excellence. (In Press)

16. Hardeman, C. \& Goethals P. L. (2011). A case study: applying Lean Six Sigma concepts to design a more efficient airfoil extrusion shimming process. International Journal of Six Sigma and Competitive Advantage, 6(3), 173- 196.

17. Huang, J. M. \& Chen, K. S. (2004). An algorithm of performance evaluation for mould development. Production Planning \& Control, 15(1), 55-62.

18. Industrial Development Bureau (2017). "Smart Electric Vehicle Development Strategy and Action Plan", Industrial Development Bureau, Ministry of Economic Affairs (Taiwan).

19. Jacobs, B. W., Swink, M., \& Linderman, K. (2015). Performance effects of early and late Six Sigma adoptions. Journal of Operations Management, 36, 244-257.

20. Kanichukattu, J. K. \& Luke, J.A. (2013). Comparison between two process capability indices using generalized confidence intervals. International Journal of Advanced Manufacturing Technology, 69(9-12), 2793-2798. 
21. Kumar, M., Antony, J., Singh, R. K., Tiwari, M. K., \& Perry, D. (2006). Implementing the Lean Sigma framework in an Indian SME: a case study. Production Planning and Control, 17(4), 407-423.

22. Lambert, F. (2017). Electric car emissions slashed by two thirds as electricity generation goes green. Retrieved June 18, 2018. https://electrek.co/2017/08/28/electric-car-emissions-electricity-generation-goesgreen/

23. Lee D. Y., Valerie M. T., Marilyn A. B. (2013), "Electric Urban Delivery Trucks: Energy Use, Greenhouse Gas Emissions, and Cost-Effectiveness" Environmental Science \& Technology, 47(14), 8022-8030.

24. Lee, K. L., \& Wei, C. C. (2010). Reducing Mold Changing Time by Implementing Lean Six Sigma. Quality and Reliability Engineering International, 26(4), 387-395.

25. Raja Sreedharan, V., Raju, R., Rajkanth, R., \& Nagaraj M. (2018). An empirical assessment of Lean Six Sigma Awareness in manufacturing industries: construct development and validation. Total Quality Management \& Business Excellence, 29(5-6), 686-703.

26. Ross P.J., (1988). Taguchi techniques for quality engineering. McGraw-Hill, New York.

27. Shamsuzzaman M., Alzeraif M., Alsyouf I. \& Khoo M. B. C. (2018). Using Lean Six Sigma to improve mobile order fulfilment process in a telecom service sector. Production Planning \& Control, 29(4), 301-314.

28. Srinivasan, K., Muthu, S., Devadasan, S. R., \& Sugumaran, C. (2016). Enhancement of sigma level in the manufacturing of furnace nozzle through DMAIC approach of Six Sigma: a case study. Production Planning \& Control, 27(10), 810-822.

29. Srinivasan, K. Muthu, S. Prasad, N. K. \& Satheesh, G. (2014). Reduction of paint line defects in shock absorber through six sigma DMAIC phases. A Journal of the Procedia Engineering, 97, 1755-1764.

30. Staffel, I., Green, R., Gross, R., Green, T., \& Scurlock, J. (2017). Electric Insights (Rep.). Retrieved June 18, 2018, from Drax group website. 
ttps://s3-eu-west-1.amazonaws.com/16058-drax-cms-production/documents/170 811_Drax_Q2_Report_06.pdf

31. Taguchi, G. (1987). System of experimental design; Engineering methods to optimize quality and minimize cost. UNIPUB, White Plains, New York.

32. Taguchi,G. (1991). Introduction to Quality Engineering. Asian Productivity Organization, UNIPUB, White Plains, New York.

33. Thomas, A. J., Francis, M., Fisher, R., \& Byard, P. (2016). Implementing Lean Six Sigma to overcome the production challenges in an aerospace company. Production Planning \& Control, 27(7-8), 591-603.

34. Trzeciak, S., Mercincavage, M., Angelini, C., Cogliano, W., Damuth, E., Roberts, B. W., Zanotti, S., \& Mazzarelli, A. J. (2018). Lean Six Sigma to Reduce Intensive Care Unit Length of Stay and Costs in Prolonged Mechanical Ventilation. Journal for Healthcare Quality. 40(1), 36-43.

35. Wang, C. C., Chen, K. S., Wang, C. H., \& Chang, P. H. (2011). Application of 6-sigma Design System to Developing an Improvement Model for Multi-process Multi-characteristic Product Quality. Proceedings of the Institution of Mechanical Engineers, Part B, Journal of Engineering Manufacture, 225, 1205-1216.

36. Wang, F. K., \& Chen, K. S. (2010). Applying Lean Six Sigma and TRIZ methodology in banking services. Total Quality Management, 21(3), 301-315.

37. Yadav, G., Seth, D., \& Desai, T. N. (2018). Application of hybrid framework to facilitate lean six sigma implementation: a manufacturing company case experience. Production Planning \& Control, 29(3), 185-201. 